\title{
Assessing Research Productivity
}

\section{Sara Thomas Rosen, Dean of Arts and Sciences Georgia State University}

$\mathbf{U}$ niversities aspire to excellence in their classrooms, in their sports arenas, in their residence halls and cafeterias, and in the services they provide students. Research universities additionally aspire to excellence in research and scholarship. Research and scholarship aspirations create additional responsibilities for administrators: They must hire, develop, and encourage research-productive faculty; they must shore up weak departments and programs while preserving high-performing units; and they must lure top faculty from other institutions while defending their own research stars from well-funded poachers.

Whether research and scholarship at a university grow or shrink over time depends upon the decisions that administrators make. The best decisions are datadriven. Decisions aimed at increasing research and scholarship require large quantities of data, including data that extend beyond one's own institution. For example, administrators must compare their own institution with others in order to learn how often art history faculty ought to publish books, or to learn how many articles per year an organic chemistry laboratory should produce, or to learn which of their own faculty are nationally prominent.

Data summarizing faculty activity are available commercially although at a steep price. The cost-benefit ratio of purchasing access depends upon how well an institution uses the data. The present paper demonstrates the value of data about faculty activity by working through actual data from the University of Kansas, a public research university.

The University of Kansas (KU) is a member of the Association of American Universities (AAU), one of sixty-two public and private institutions in the U.S. and Canada. AAU membership is awarded to universities that excel in research and scholarship as operationalized primarily by the following criteria:

- number of publications; ${ }^{1}$

- number of citations;

- total grant dollars;

- number of national academy memberships.

The AAU's attention to citations reflects a core value: Research and scholarly activity ought to have an impact. Citation counts provide the most widely accepted measure of impact.

Operationally, a publication's citation count equals the number of other publications that cite it. A substantial literature discusses the pros and cons of citation counts and various weighted alternatives (e.g., the $g$-index ${ }^{2}$ and one or another version of the $h$-index ${ }^{3}$ ). The present paper avoids the citation count controversy on the grounds that, at this time, no practical alternative exists to measuring impact through citations.

Publication counts (how many publications) and grants (how many grants and their dollar value) also measure what faculty are accomplishing. The present 
paper treats four measures-citation counts, publication counts, number of grants, and grant dollars - as jointly illuminating faculty members' research and scholarly contributions, or faculty scholarly productivity.

At the 2014 Merrill Retreat, Joseph Steinmetz discussed what The Ohio State University uses scholarly productivity data for: to compare OSU faculty with those of other institutions, to compare OSU departments and programs with those of peer institutions, to prepare program review evaluations at OSU, and to make decisions about where to invest OSU's resources. The present paper extends Steinmetz's recommendations by showing how to use productivity data to identify factors that influence productivity.

\section{Methods}

Academic Analytics Dataset and Major Metrics

Academic Analytics furnishes counts and sums of book publications, journal publications, citations, grants, grant dollars, and conference talks. ${ }^{4}$ Counts and sums are difficult to compare across universities because they depend upon the size of a department or program. The Academic Analytics database therefore adjusts counts and sums by dividing by the number of faculty in a department. The present paper examined eleven measures. The measures examined are listed in Table 1.

Table 1: Measures of Research Productivity

\begin{tabular}{|l|c|c|}
\hline \multicolumn{1}{|c|}{ Measure } & $\begin{array}{c}\text { Type of } \\
\text { Measure }\end{array}$ & $\begin{array}{c}\text { Collection } \\
\text { Period }\end{array}$ \\
\hline Percent of Faculty Who Published a Book & Percentage & $2005-2014$ \\
\hline Mean Number of Books Per Faculty Member & Ratio & $2005-2014$ \\
\hline Percent of Faculty Who Published a Journal Article & Percentage & $2011-2014$ \\
\hline $\begin{array}{l}\text { Mean Number of Journal Articles per Faculty Mem- } \\
\text { ber }\end{array}$ & Ratio & $2011-2014$ \\
\hline Percent of Faculty With a Citation & Percentage & $2010-2014$ \\
\hline Mean Number of Citations per Faculty Member & Ratio & $2010-2014$ \\
\hline Mean Number of Citations per Article & Ratio & $2010-2014$ \\
\hline Percent of Faculty Awarded a Grant & Percentage & $2011-2014$ \\
\hline Mean Number of Grants per Faculty Member & Ratio & $2011-2014$ \\
\hline Mean Grant Dollars per Faculty Member & Ratio & $2011-2014$ \\
\hline Mean Dollars per Grant & Ratio & $2011-2014$ \\
\hline
\end{tabular}


At present, the database only collects citations of journal articles found within journal articles. The dataset does not yet collect citations of books or citations found within books.

\section{Institutions}

The present paper compared the University of Kansas to its peer institutions, some comparable and others aspirational. KU's peer institutions (as approved by the Kansas Board of Regents) are:

- Indiana University

- Michigan State University

- University at Buffalo

- University of Colorado - Boulder

- University of Florida

- University of Iowa

- University of Missouri - Columbia

- University of North Carolina Chapel Hill

- University of Oregon

- University of Virginia

Although the database tracks the activity of individual faculty, data about a university's individual faculty are visible only to subscribers within that university. In the interest of preserving confidentiality, this paper avoided identifying individual faculty at KU. The paper also de-identified KU's peer institutions (KU is labeled " $\mathrm{K}$ " in the figures that follow).

\section{Departments}

Nine departments were selected for detailed analysis before examining any productivity data. Several criteria guided the selection. First, all nine departments are typically found within a college of (liberal) arts and sciences (as opposed to, say, computer science, which often resides within schools of engineering). Second, departments had to have at least ten faculty members in each of the eleven institutions. Third, the selection process avoided departments that were heterogeneous across universities because of highly specialized subfields.

The next step was to prepare tables and graphs that summarized faculty productivity within all nine departments of all eleven institutions. Department-bydepartment examination of the results found three departments for which the results pointed to interesting patterns of productivity. Those three departments included one in the social-behavioral sciences (SS1), one in the natural-mathematical sciences (NS1), and one in the humanities (H1). The Results section begins by examining SS1, NS1, and H1 in depth, and concludes by summarizing the productivity of all nine departments.

\section{Results}

Social Science - SS1

As measured by the number of faculty, department SS1 is slightly small relative to KU's peer institutions.

\section{Books}

Sixty-seven percent (67\%) of the KU's SS1 faculty published a book during the Academic Analytics data collection period, slightly higher than average for the peers. (The percentages for the peers ranged from $54 \%$ to $76 \%$.) Averaged over all of the department's faculty (ignoring whether they published a book), the mean number of books per faculty was 1.2 (Figure 1), slightly higher than average for the peer institutions. 
Figure 1: SS1 book publications per faculty member

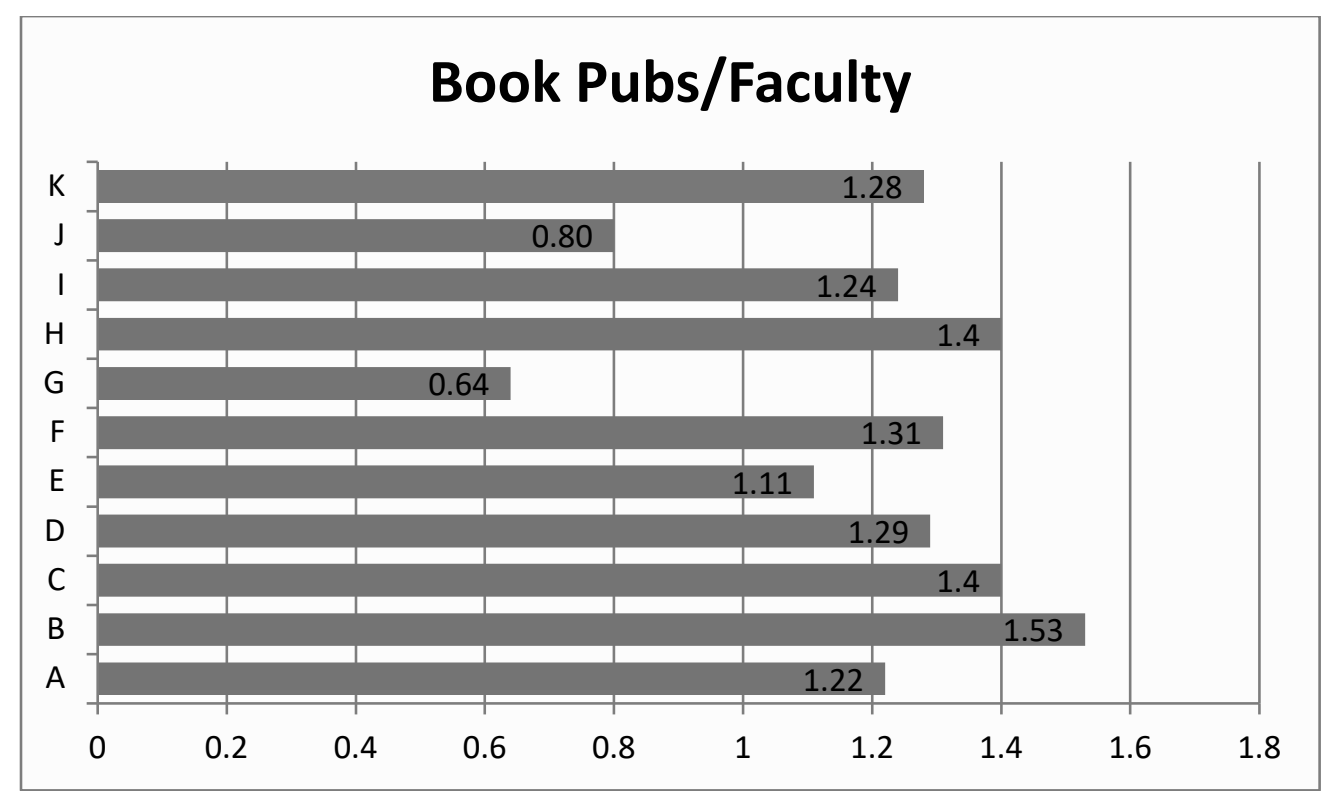

\section{Articles}

Only 39\% of the KU SS1 department's faculty published an article during the Academic Analytics data collection period. Among the peer institutions, the next lowest value was $67 \%$ and the me- dian was between $79 \%$ and $83 \%$. Averaged over all of the KU SS1 department's faculty (no matter whether they published an article), the mean journal publications per faculty was 1.39 (Figure 2). The median value among the peer institutions was over 3.5 journal publications.

Figure 2: SS1 journal publications per faculty member

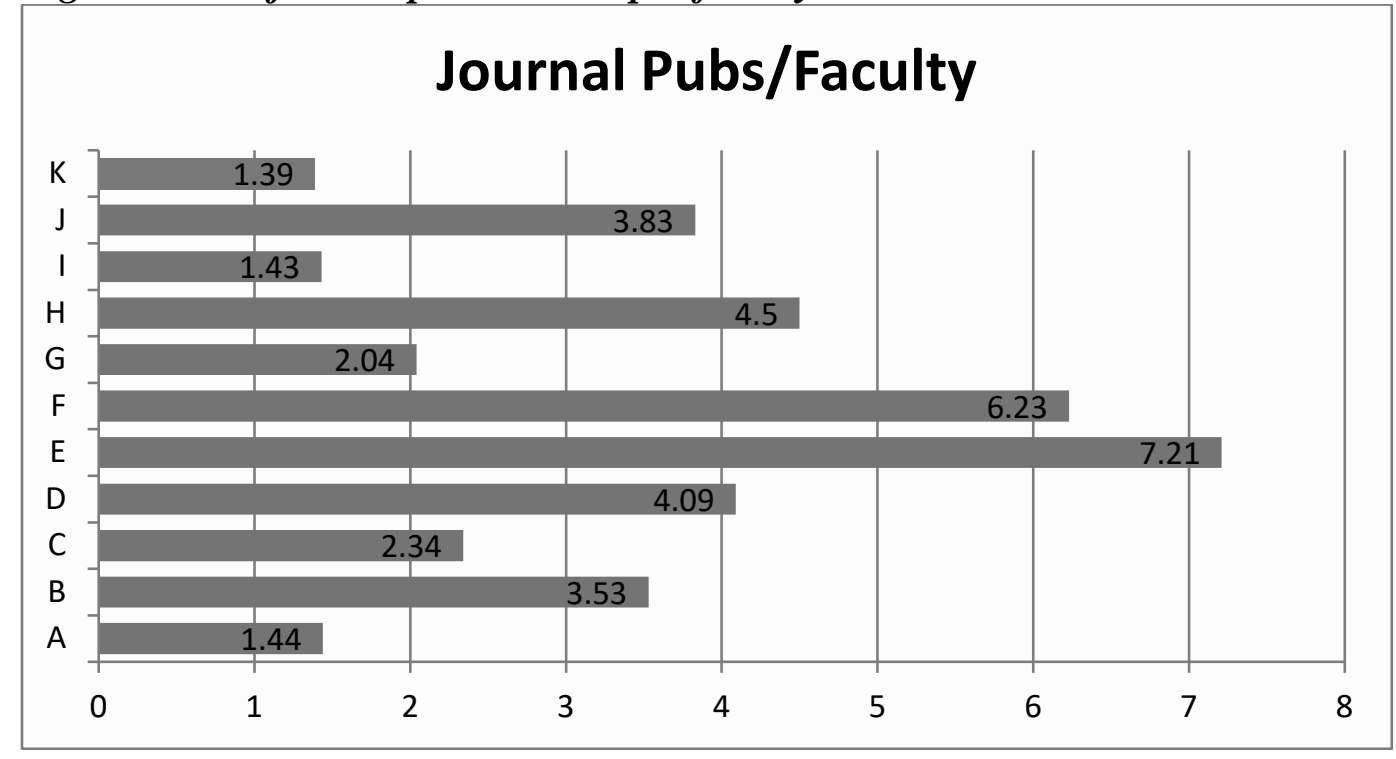




\section{Citations}

For KU's SS1 faculty, the mean num-

In contrast to the overall citation ber of citations of KU faculty's journal articles was 18 (Figure 3), about average relative to the peers. counts, the mean number of citations per journal article was extraordinarily high (Figure 4 ) at 8.95 citations. The faculty of the peer institutions typically had 5 to 6 citations per journal publication.

Figure 3: SS1 Citations per faculty member

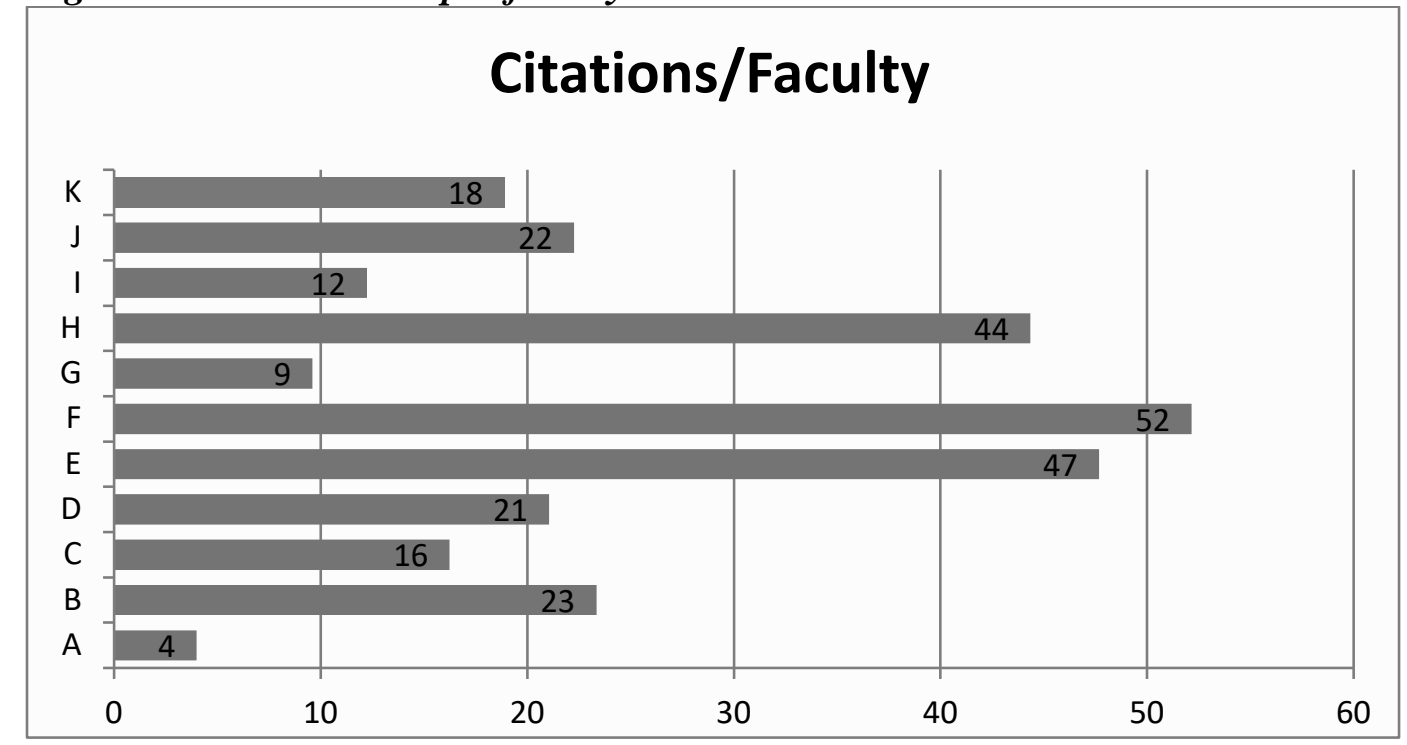

\section{Figure 4: SS1 Citations per publication}

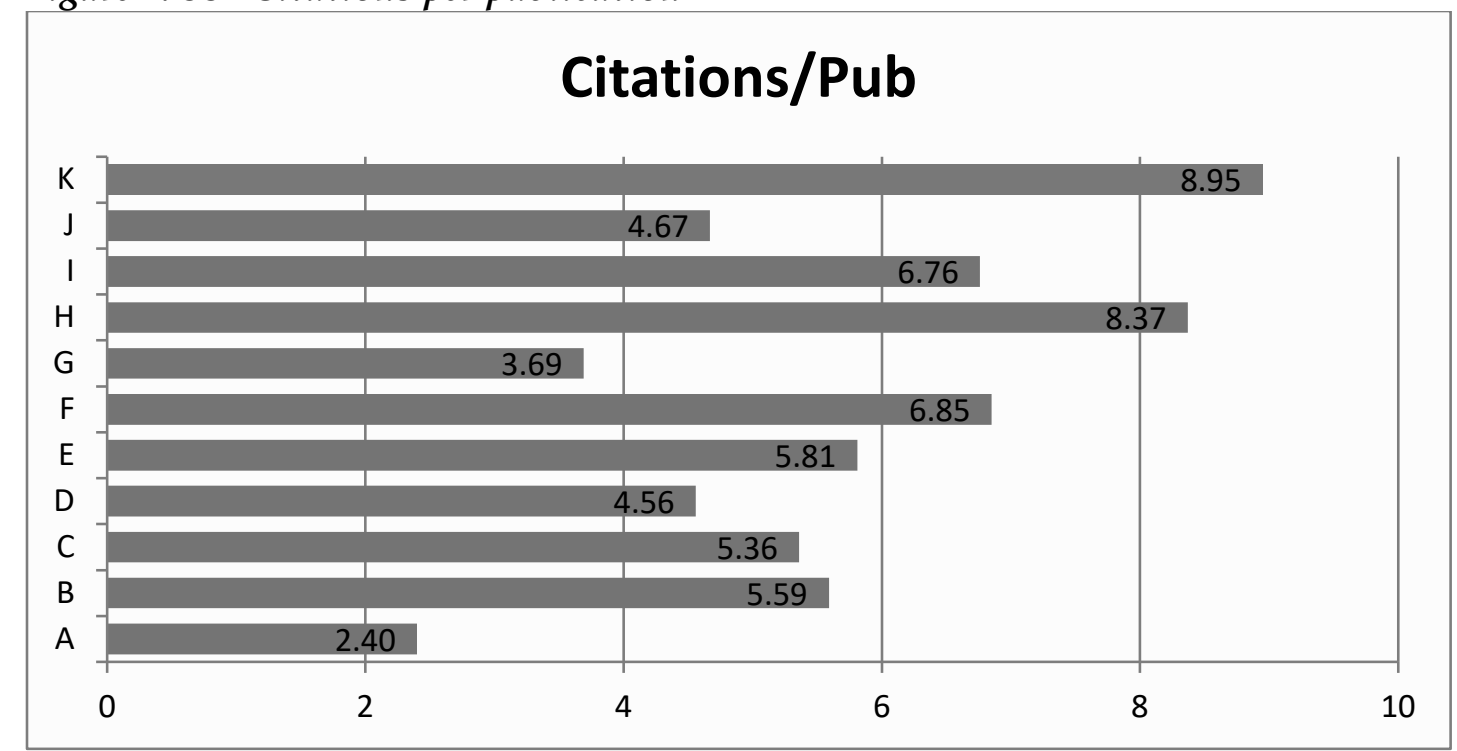




\section{SS1: Discussion of research produc- tivity}

Within the SS1 department, more faculty have published books (67\%) than journal articles (39\%). ${ }^{5}$ Nonetheless, the SS1 faculty have an average number of citations. The average citation value results from a balance of two findings: first, the small number of SS1 faculty who have been publishing articles, and second, the high mean number of citations per publication. Those SS1 faculty who have been publishing journal articles have produced highly cited - impactful-work.

Inspection of the data for individual Kansas faculty (only available to registered KU users) showed that only two if KU's SS1 faculty had been publishing journal articles. (The same two faculty members have been receiving substantial grants, in contrast to the other SS1 faculty). The two faculty who have been publishing articles, accruing citations, and winning grant awards are the department's two most senior faculty members.

The SS1 department's books-ratherthan-journals publishing pattern is problematic for the university as a whole, because the AAU's metrics reward journal articles and grants more than books. The department's focus on books impedes KU's efforts to remain in the AAU.

One could argue that, within the field of the SS1 department, books contribute as much or more than journal articles, even though the SS1 departments of KU's peer institutions are far more oriented to- wards journal publications. The argument is flawed, however, because $33 \%$ of KU's SS1 faculty did not publish a book during the Academic Analytics ten-year collection period. Even ignoring the two highly cited senior faculty, several SS1 faculty did not publish a book.

The Academic Analytics data indicate that KU's SS1 faculty productivity is generically low. According to the Academic Analytics database, only two very senior faculty members are publishing a substantial number of journal articles; the department has no young, productive journal-oriented faculty. It has been twenty years since the department last hired and retained a productive journal-oriented faculty member. The data suggest a question: Why? What caused the twenty-plus year drought? The answer may lie in the department's hiring, retention, and mentoring practices, or in the department's and college's tenure and promotion standards. A first step towards increasing productivity would be to identify and correct the hiring and promotion practices that led to non-productive faculty.

\section{Natural Science - NS1}

Books are sufficiently rare within NS1's field so as to obviate comparative analyses.

\section{Articles}

Within KU, almost all (96\%) of the NS1 department's faculty have published an article during the Academic Analytics four-year data collection period. The two lowest values among the peers are $85 \%$ and $90 \%$. 
The number of journal publications per faculty member was 12.6 (Figure 5), a somewhat low value relative to KU's peers. Half of the peers had more than 15 journal publications during the same time period.

Figure 5: NS1 Journal publications per faculty member

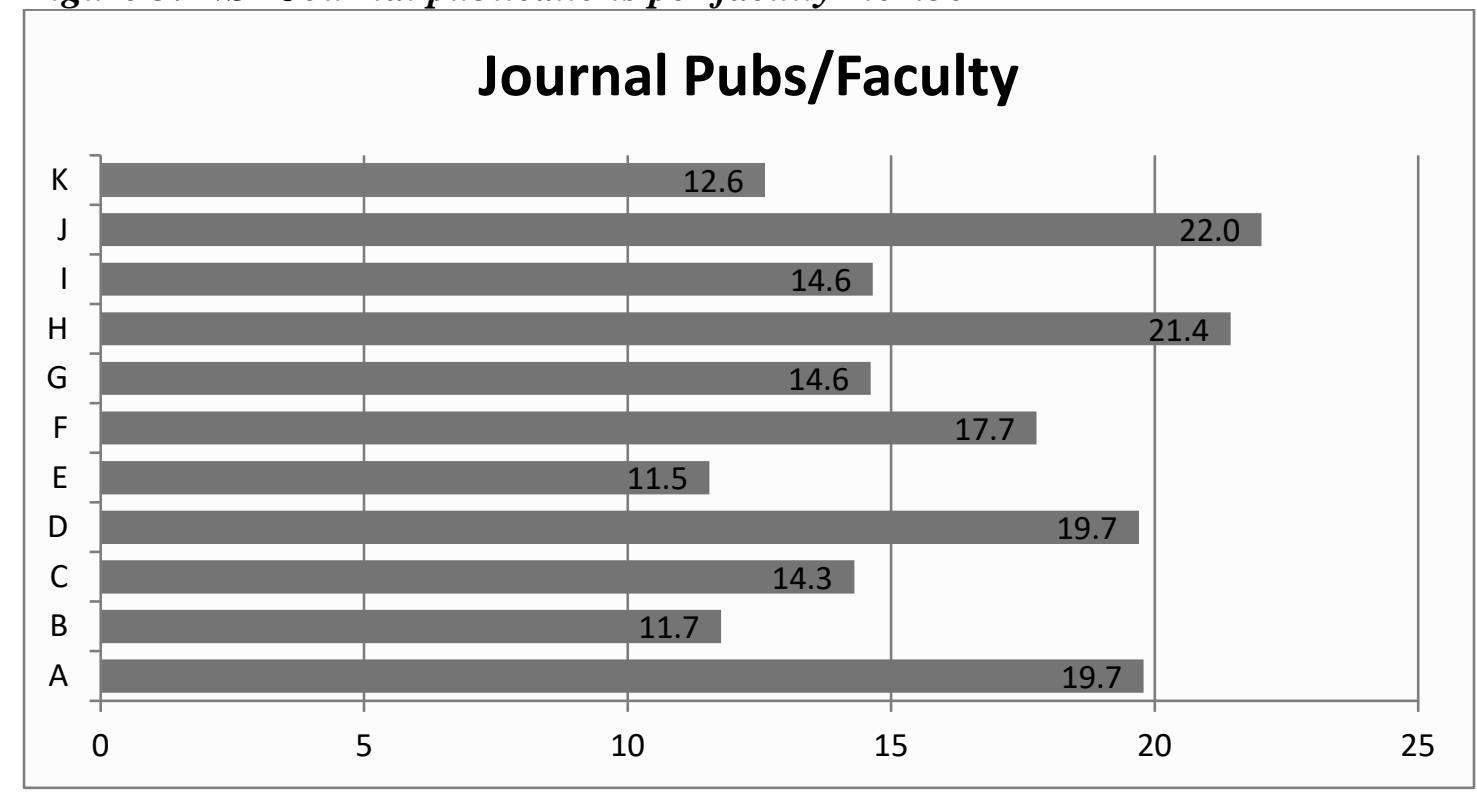

\section{Citations}

KU's NS1 faculty accrued 185 citations during the five-year collection period (Figure 6). The value of 185 is lower than for any of KU's peers. Half of the peers had means above 300 citations per faculty member. The highest of the peer departments had a mean almost four times that of KU.

Figure 6: NS1 Citations per faculty member

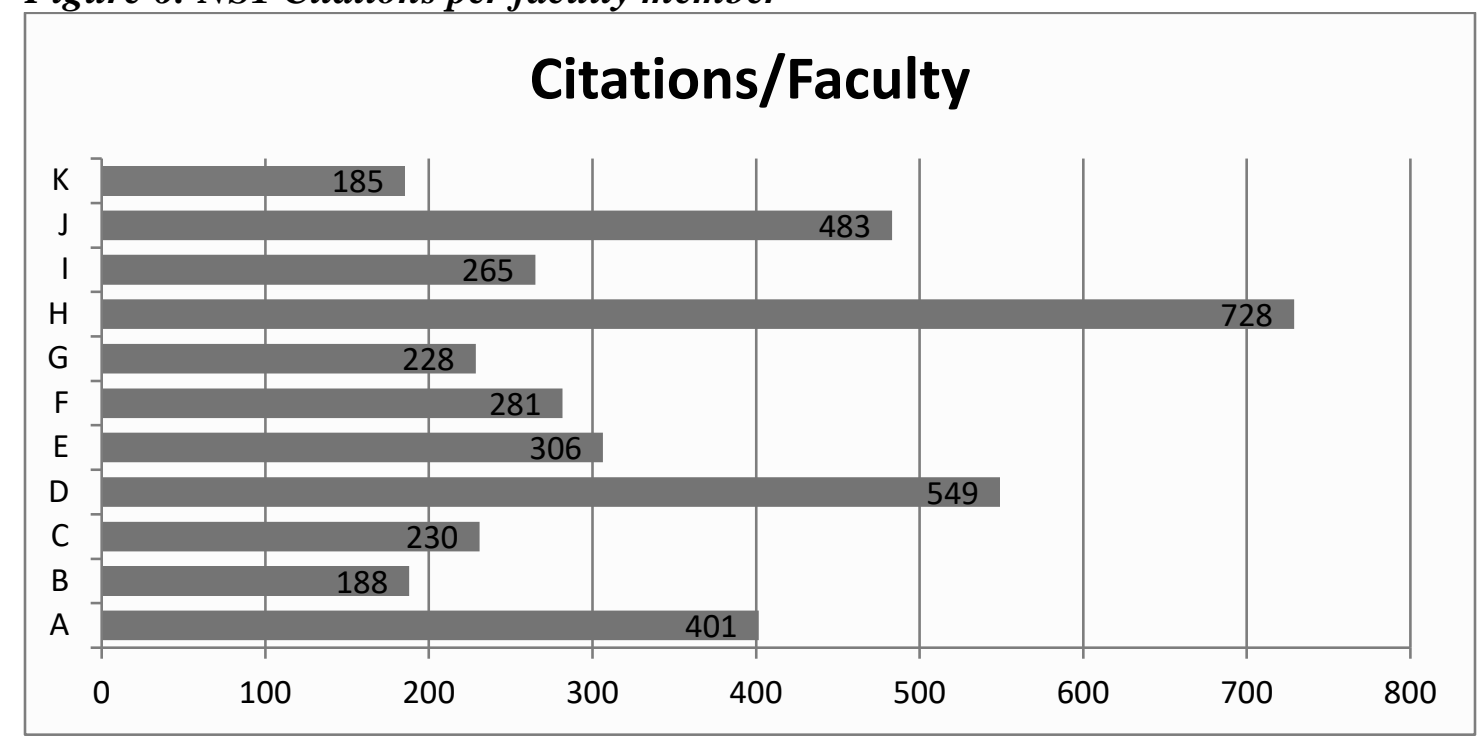


Figure 7: NS1 Citations per publication

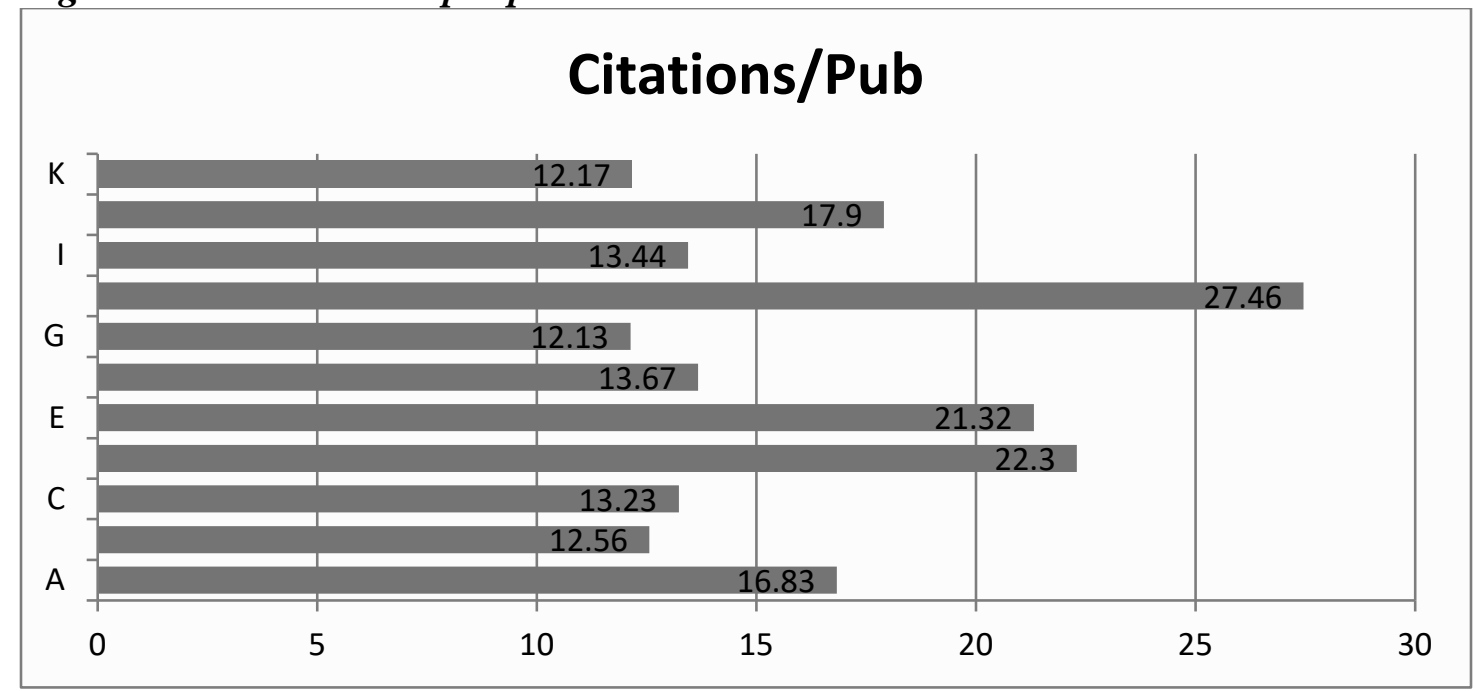

KU's faculty received relatively few citations compared with NS1 faculty at peer institutions (Figure 7). KU's mean citations per article of 12.17 virtually tied with the lowest value among the peer institutions. Half of the peers averaged above 15 citations per publication.

\section{Grants}

Grant activity in the natural sciences is crucial to faculty research productivity and reflects peer confidence in the recipients' research competence. Most (79\%) of KU's NS1 faculty had an active grant during the four-year data collection period. The percentage of KU's faculty with a grant was higher than all but one of the peer institutions.

Figure 8: NS1 Percent of faculty with a grant

\section{Pct Faculty With Grant}

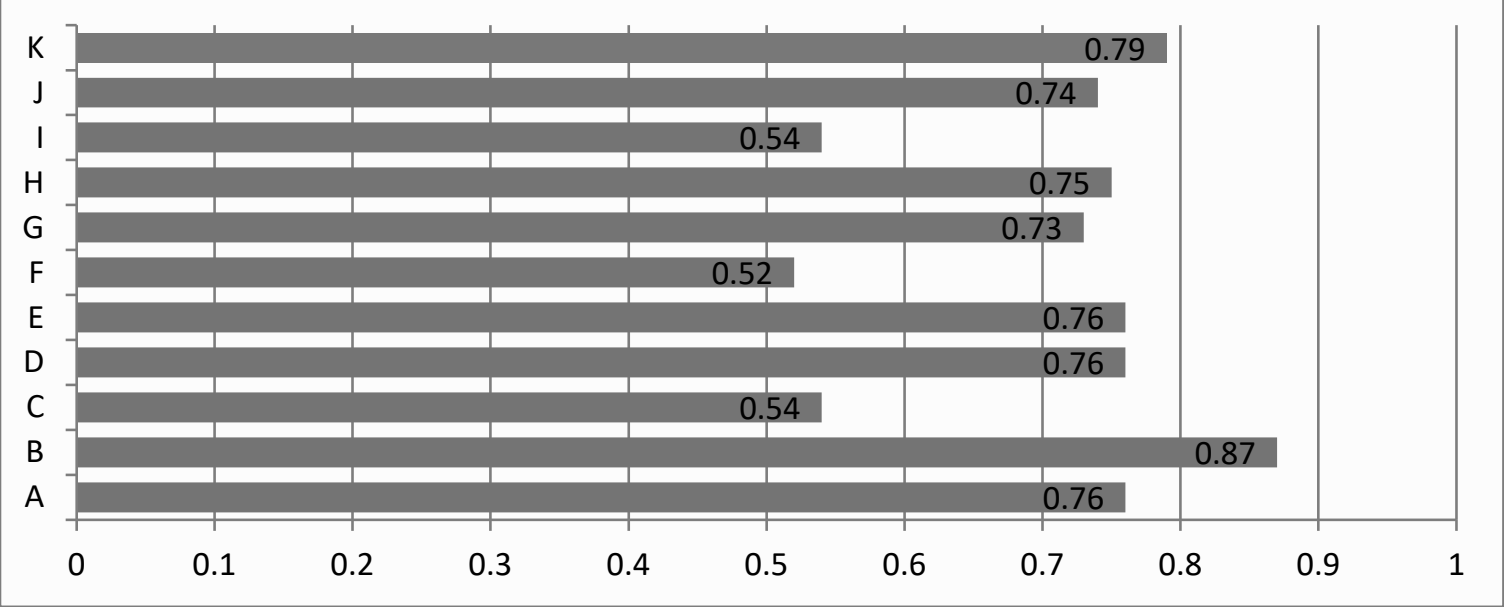


Figure 9: NS1 Grants per faculty member

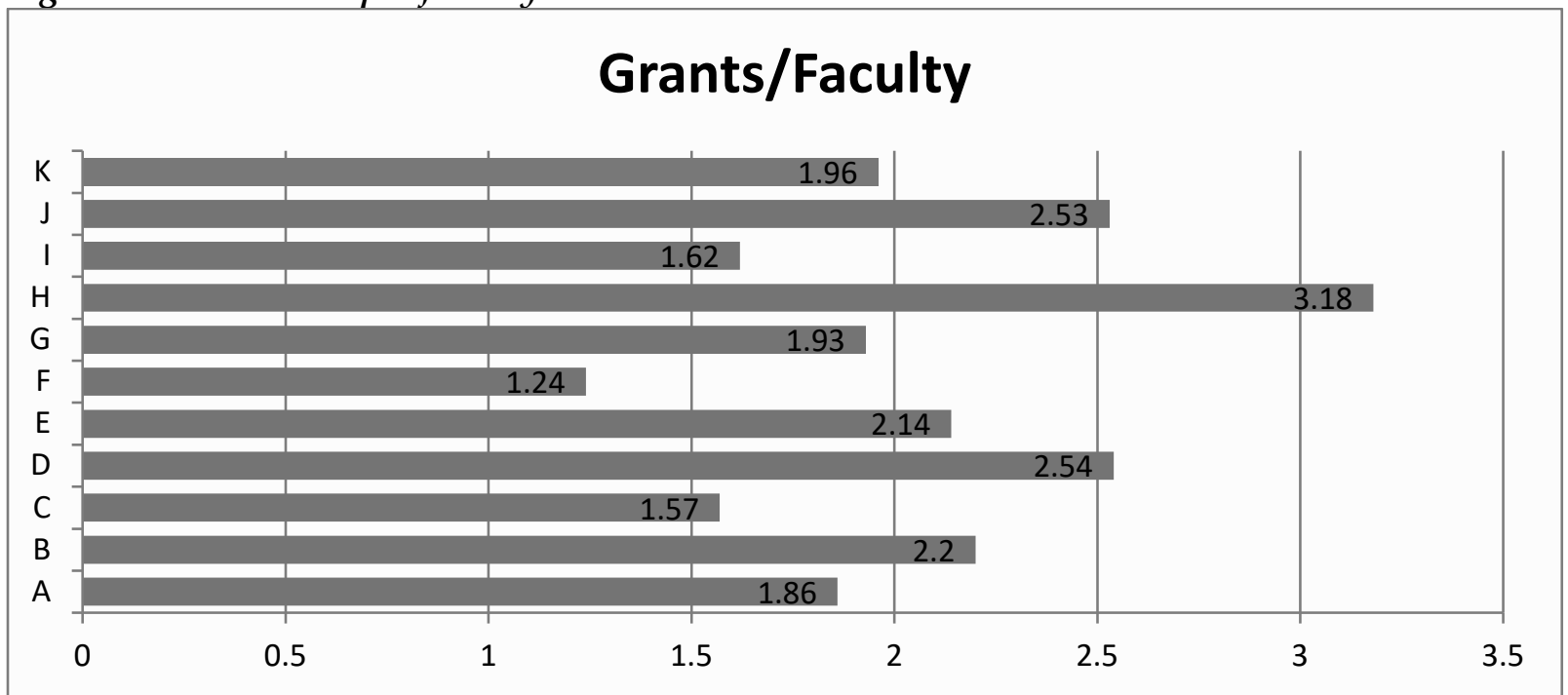

Although most of the NS1 faculty at KU had a grant, the number of grants per faculty member at KU (1.96) was average compared with the peer institutions (Figure 9).

KU's NS1 department was average in grant dollars per faculty member
$(\$ 353,000)$ and dollars per grant (\$180,000; Figures 10 and 11). Overall, KU's NS1 faculty were unusually likely to have one or more grant, but they obtained an average volume of grant funding.

Figure 10: NS1 Grant dollars per faculty member

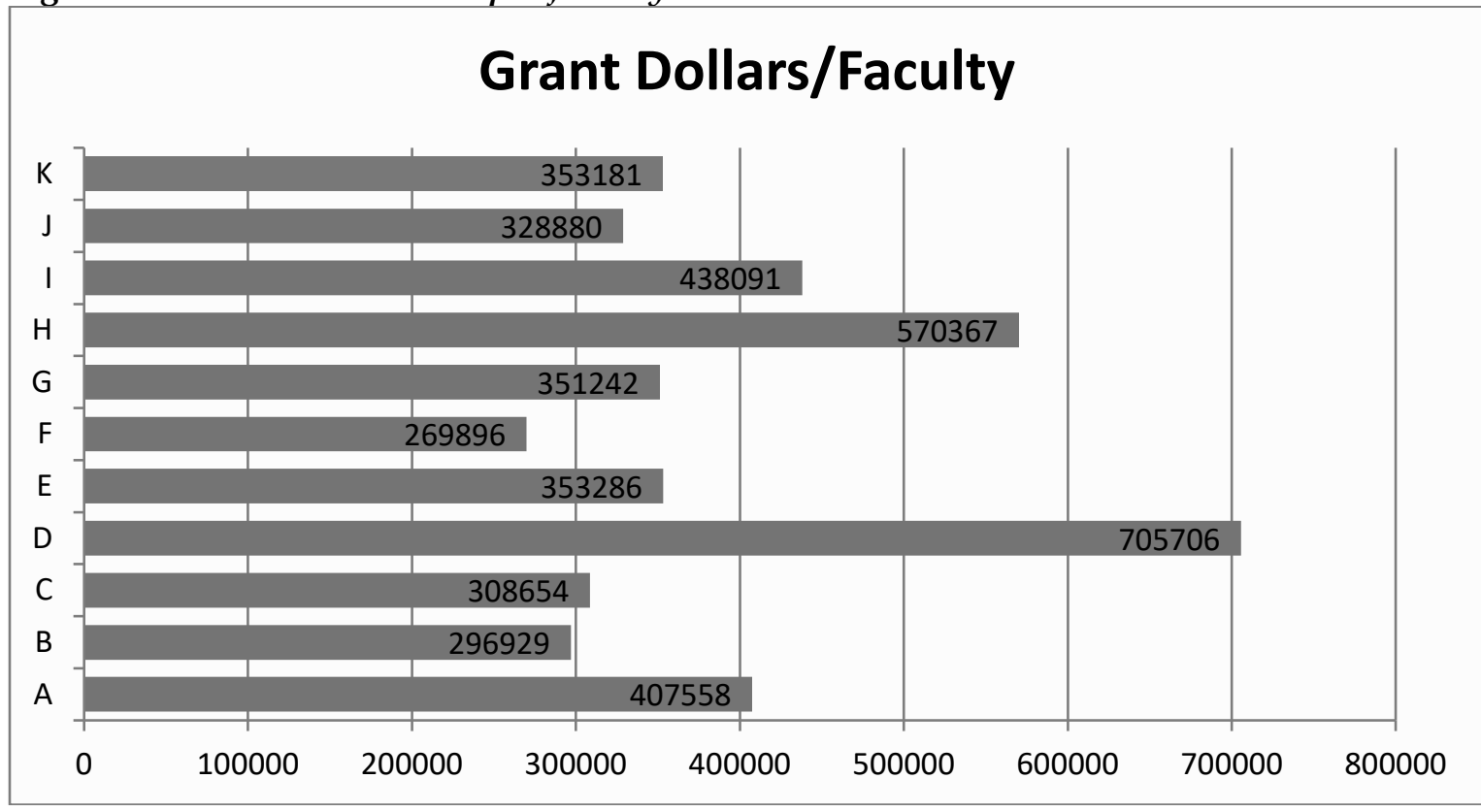


Figure 11: NS1 Dollars per grant

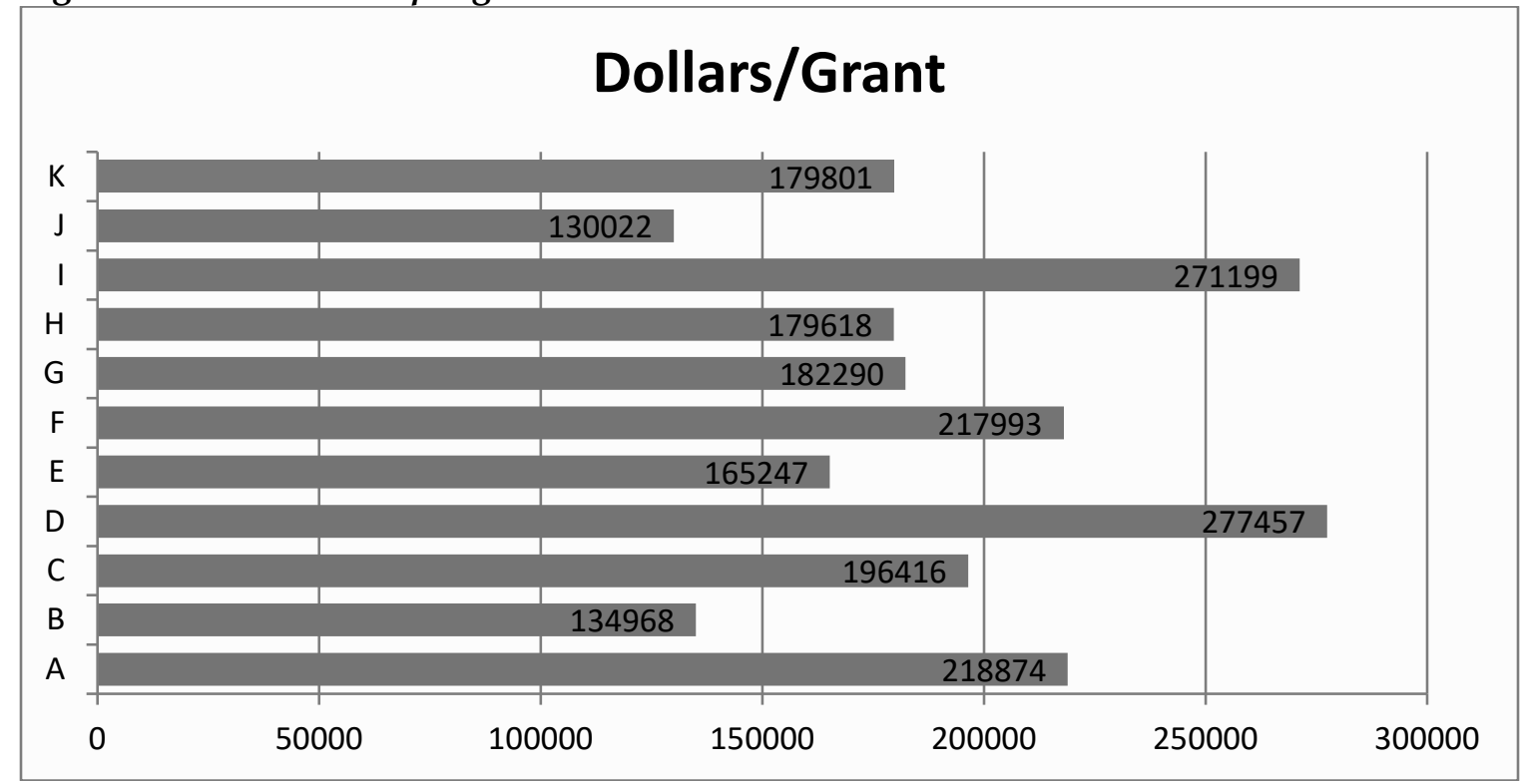

NS1: Discussion of research productivity

The NS1 data formed a striking pattern:

1. Almost all of KU's NS1 faculty published one or more journal articles during the 2011-2014 period; and almost all received at least one citation.

2. The number of articles per faculty member was slightly lower for KU than for KU's peers.

3. The number of citations per faculty member was extremely low for KU's faculty, as was the number of citations per publication.

4. KU's NS1 faculty received grants and grant dollars at roughly the same rate as the median values for the peer institutions.

Integrating the four points above suggests the following conclusion: The faculty in KU's NS1 department are relatively active in terms of publishing and grant activity, but the work done at KU has a minimal impact on the field. Researchers at other institutions pay little attention to the research performed by KU's NS1 department.

The data and the conclusions suggest an essential question: Why are citations to KU's research so low; why do KU's researchers have so little impact? The question's importance demands further explorations:

1. Is the low impact of KU's research an artifact of the subfields that KU's faculty investigate?

2. Alternatively, are KU's faculty publishing "small" articles that attract little attention?

3. Are KU's faculty publishing in journals that most of their peer colleagues ignore?

4. Does the low impact of work coming out of KU reflect poor mentoring or tenure advice (e.g., "slow, steady, and unexciting work will earn tenure and promotion")? 
Answering the questions requires a level of technical expertise that a university's central administration cannot possess. An external review team should examine the department's research activity and why the research impact is so low.

\section{Humanities - H1 \\ Books}

Book publications provide the predominant medium for disseminating scholarship within the humanities. In
KU's H1 department, $42 \%$ of the faculty published a book during the 2005-2014 collection period. The $42 \%$ value is slightly low relative to the peer institutions, for which the median publication rate was $55 \%$ to $60 \%$.

Although relatively few of KU's H1 faculty published books, the mean number of books faculty member (1.83) was slightly high relative to the peers (Figure 13).

Figure 12: H1 Percent of faculty with a book publication

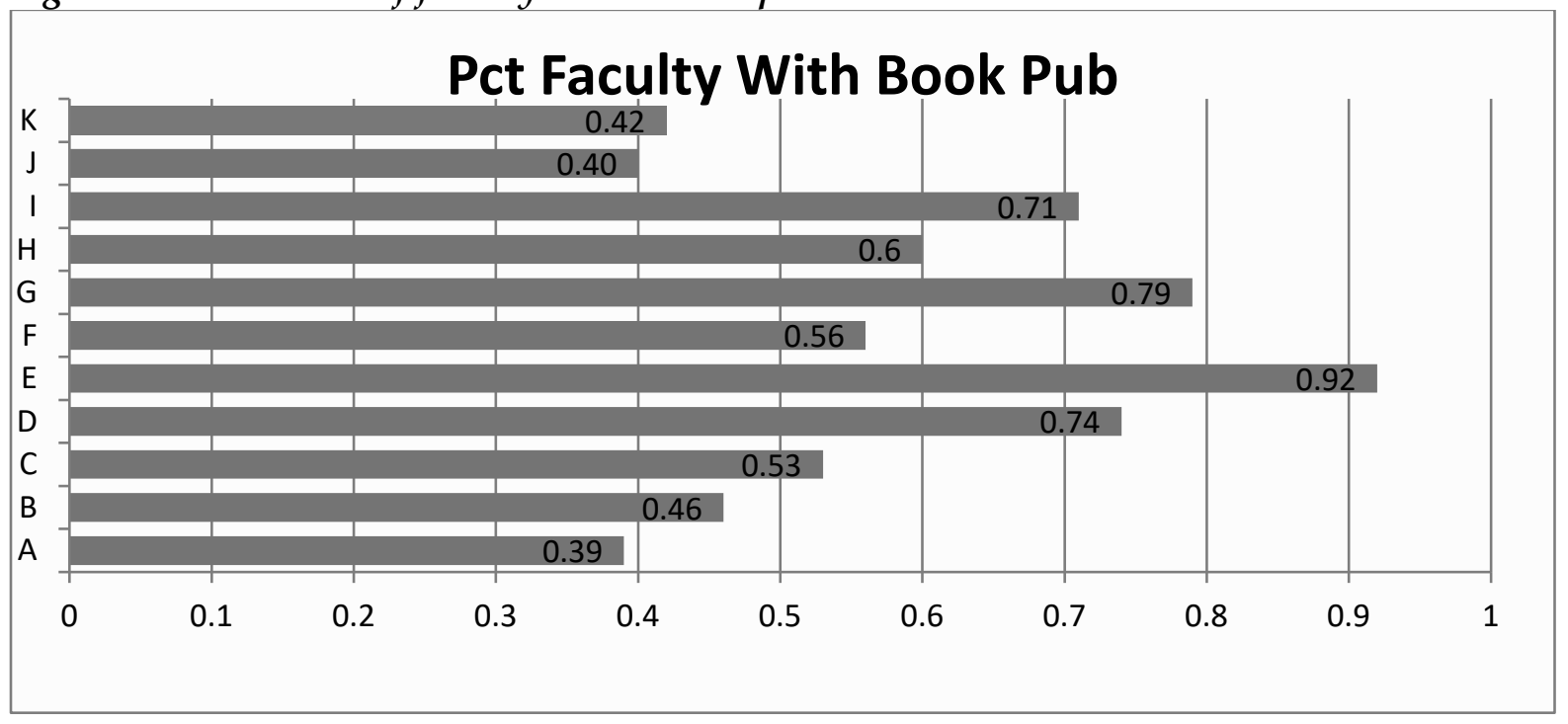

Figure 13: H1 Book publications per faculty member

\section{Book Pubs/Faculty}

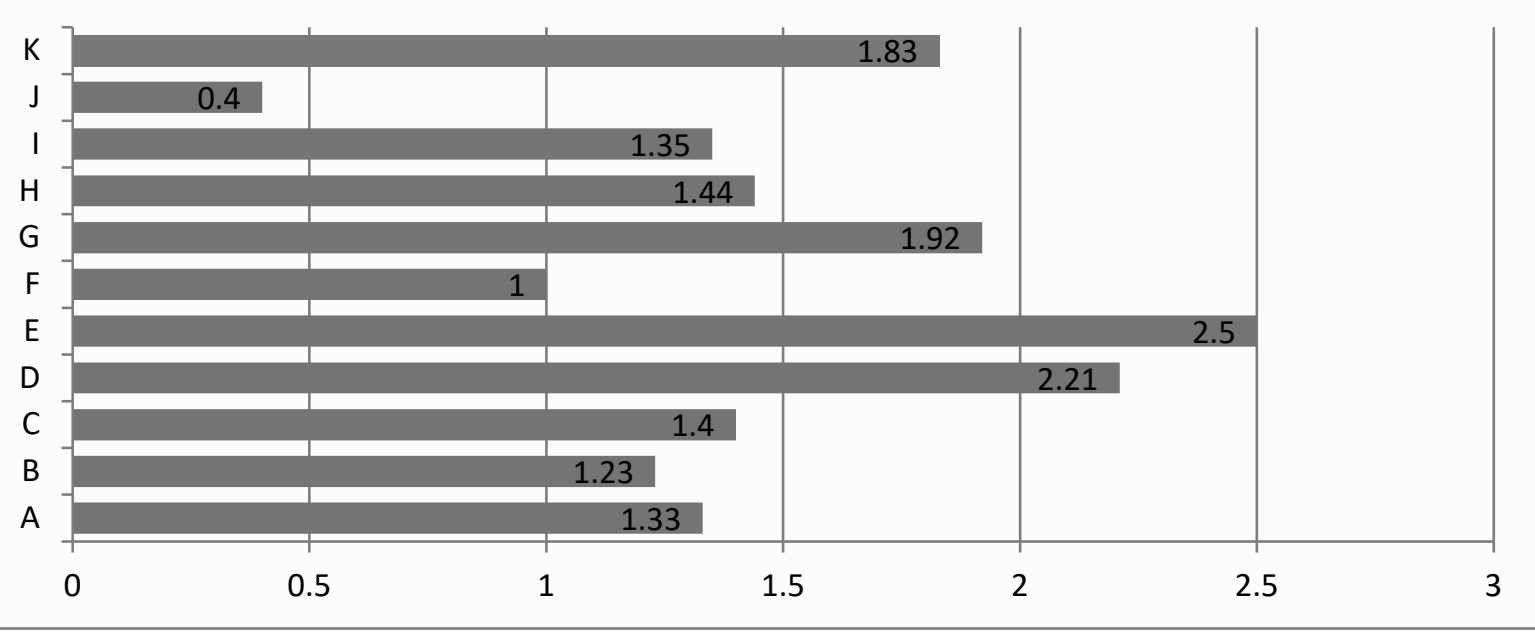


The two findings suggest that those faculty members who do publish books do so at a high rate. Examination of faculty-level data revealed that the bookpublishing faculty averaged an impressive 4 books each during the 10-year Academic Analytics collection period.

\section{Articles}

Most of the $\mathrm{H} 1$ faculty (83\%) pub- lished a journal article during the fouryear journal article collection period-a high value compared with the peer institutions (Figure 14).

KU's H1 faculty published a relatively large number of journal articles (Figure 15). Only two peer institutions had higher means for number of journal articles per faculty.

Figure 14: H1 Percent of faculty with a journal publication

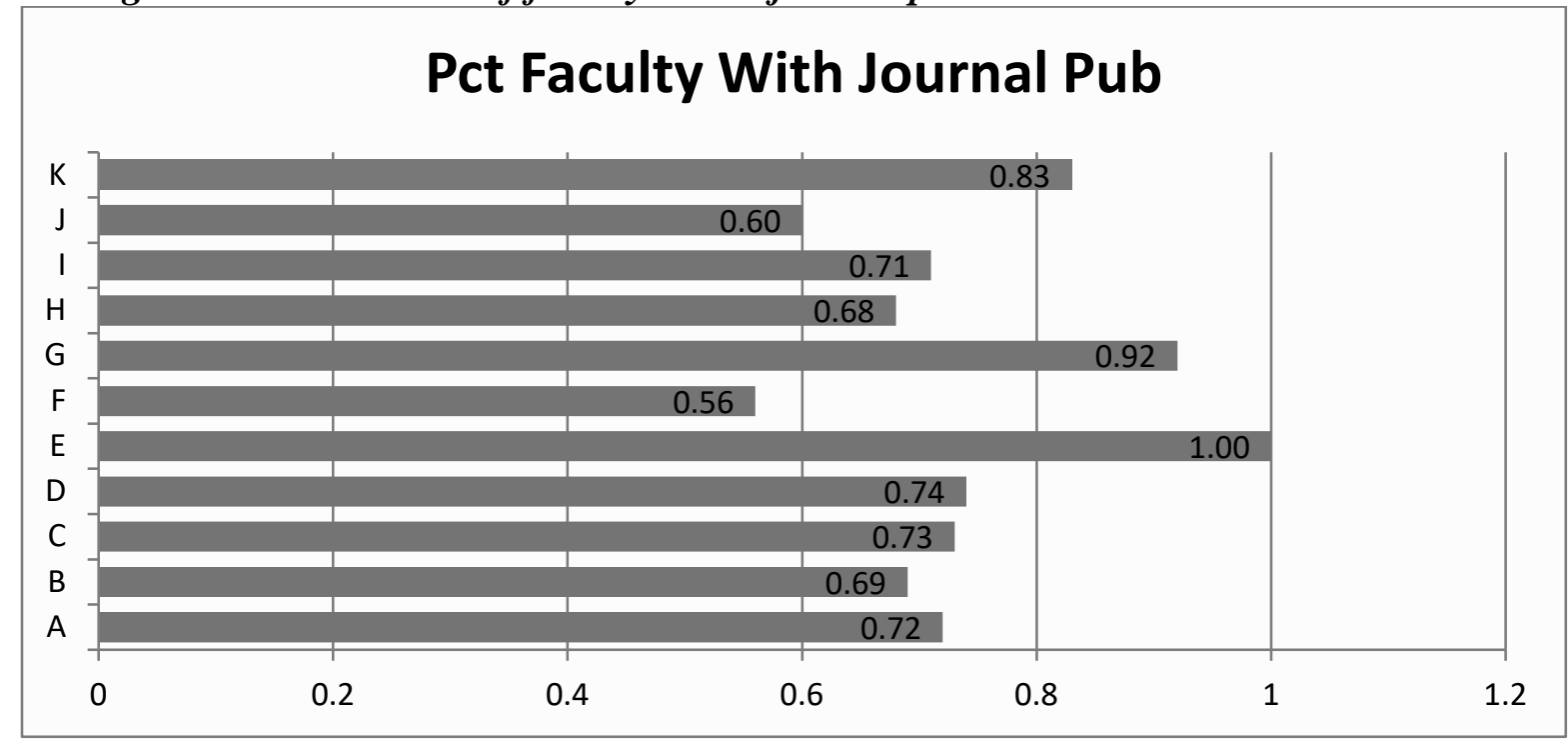

Figure 15: H1 Journal publications per faculty member

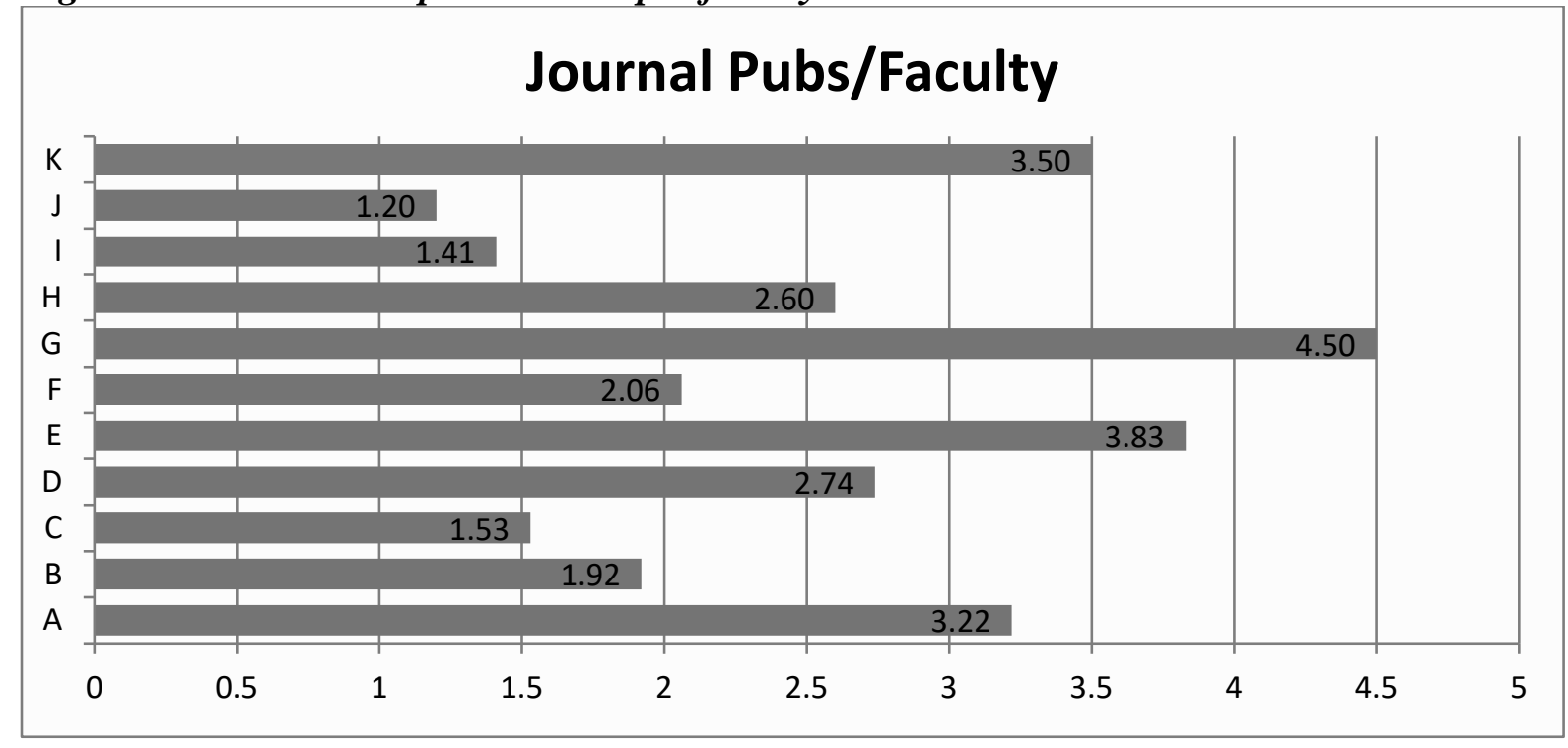




\section{Citations}

The citation data for KU's H1 faculty showed average performance relative to the peers. KU's faculty averaged $6.92 \mathrm{ci}$ tations; only two of the peer institutions had means greater than 10 (Figure 16).
Across the peer institutions, $\mathrm{H} 1$ journal articles were rarely cited: a mean of 1.66 times for KU's faculty (Figure 17), and never more than 5 times each for the peer institutions.

\section{Figure 16: H1 Citations per faculty member}

\section{Citations/Faculty}

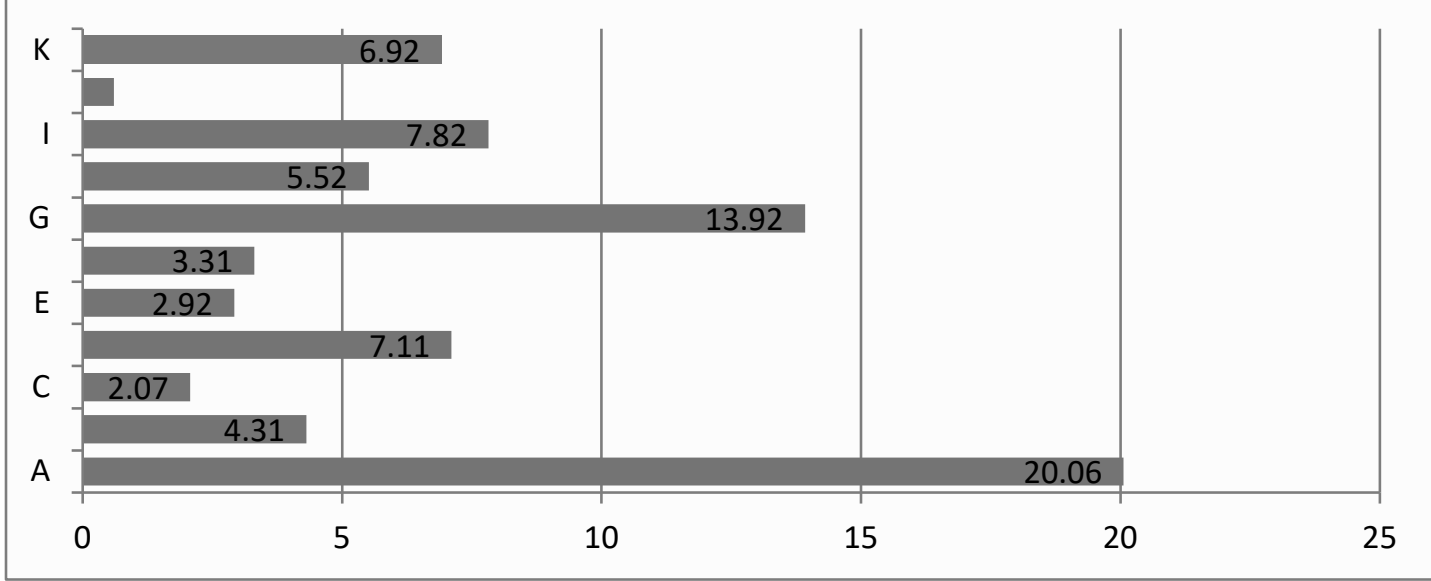

Figure 17: H1 Citations per publication

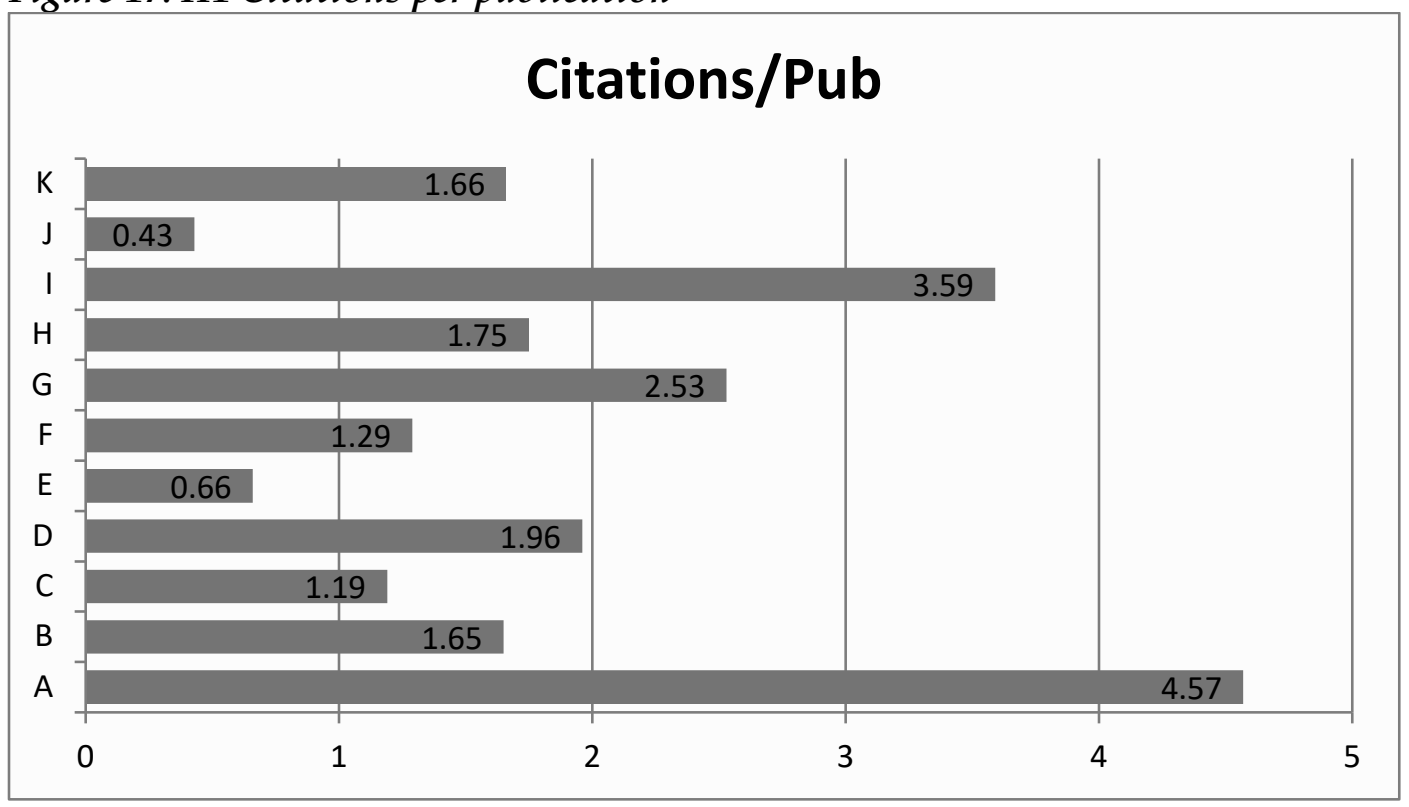




\section{H1: Discussion of the research productivity}

On the whole, the faculty of KU's H1 department have been keeping busy. Some of the faculty have a strong record of publishing books; some have a strong record of publishing journal articles.

The H1 results suggest a question: Who has been doing what kind of publishing? Are the department's faculty bifurcated, with some writing books and others writing articles? Or have the same faculty been responsible for both types of publications?

An examination of the faculty-level data showed that two senior faculty members had above-average numbers of books, and three junior to mid-career faculty members had above-average numbers of journal articles. The department's

other faculty had average to belowaverage records in publishing books and articles.

Averaged across the entire department, H1 looks relatively productive. However, the data for individual faculty reveal that fewer than half have been producing the majority of the department's scholarly output.

\section{Meta-metrics}

The Academic Analytics database lists most measures in two forms - means and percentages as shown in the previous graphs, and the corresponding standard scores ( $z$-scores: mean $=0$, standard deviation $=1)$. The $z$-scores are computed with respect to all 409 research universities in the dataset.
The constant $0-1$ scale allows one to compare departments within a university or to compare one institution to another. One can also use the $z$-scores to invent new indices, two of which follow:

- Productivity Index: The mean of the $z$-scores for Number of Books per Faculty and Number of Journal Articles per Faculty

- Impact Index: The z-scores for Article Citations per Faculty

The Productivity Index measures a department's output relative to department-matched peers. The Impact Index measures a department's impact relative to department-matched peers. For both indices, a score of $z=0$ indicates that a department is average relative to the peer institutions. Positive scores indicate superior performance and negative scores indicate inferior performance. "Average" performance was (arbitrarily) defined as a $z$ score between -0.2 and +0.2 .

Values of the two indices were computed for the full set of nine departments mentioned in the Methods section (three in the humanities, three in the social and behavioral sciences, and three in the natural and mathematical sciences).

Productivity metric. Three of the nine KU departments have been more productive than average, five about average in productivity, and one less productive than average (Table 2). Productivity was unrelated to broad field: The above-average departments included one in the natural sciences and two in the humanities; the below-average department was in the natural sciences. 
Table 2: KU Department Means for Productivity

$(z$ (Number Books $)+z$ (Number Articles) / 2)

\begin{tabular}{|l|c|l|}
\hline \multicolumn{1}{|c|}{ Broad Field } & Productivity Index & Classification \\
\hline Natural Science & 0.44 & Above Average \\
\hline Humanities & 0.44 & Above Average \\
\hline Humanities & 0.40 & Above Average \\
& & \\
\hline Social Science & 0.14 & Average \\
\hline Social Science & 0.07 & Average \\
\hline Natural Science & 0.02 & Average \\
\hline Humanities & -0.10 & Average \\
\hline Social Science & -0.18 & Average \\
\hline Natural Science & -0.24 & Below Average \\
\hline
\end{tabular}

Table 3: KU Department Means for Impact ( $z$ (Citations per Faculty Member))

\begin{tabular}{|l|c|l|}
\hline \multicolumn{1}{|c|}{ Broad Field } & Impact Index & \multicolumn{1}{c|}{ Classification } \\
\hline Natural Science & 1.41 & Above Average \\
\hline Natural Science & -0.06 & Average \\
\hline Humanities & -0.09 & Average \\
\hline Social Science & -0.16 & Average \\
\hline Humanities & -0.17 & Average \\
\hline Humanities & -0.21 & Below Average \\
\hline Social Science & -0.22 & Below Average \\
\hline Natural Science & -0.33 & Below Average \\
\hline Social Science & -0.39 & Below Average \\
\hline
\end{tabular}

Impact metric. Only one KU department was above-average on the impact index. That lone department had an astonishingly high mean of 1.41 (Table 3) - a higher impact score than any of the peer institutions in that field.

KU's other eight departments all had negative $z$-scores for impact. Four had sufficiently low impact scores to meet the below-average statistical criterion.

\section{Discussion of Meta-metrics}

With the exception of one of the nine departments, KU's faculty have been putting their time, effort, and resources into producing articles that are rarely cited. The finding raises two obvious and obviously serious questions: (a) Why have KU faculty been producing under-cited work; and (b) how can KU improve citation scores?

Questions abound: Has the University of Kansas been making poor hiring 
decisions? Have faculty mentors been giving conservative advice about how to win tenure? Have KU's standards for hiring, promotion, and post-tenure review been too relaxed? Are the reasons for low citations the same or different across schools and departments?

During the last few years, the University of Kansas has tried to raise KU's research profile by hiring twelve highly productive faculty members, the Foundation Distinguished Professors. These new faculty members will "bring" their citations with them because the Academic Analytics database awards citation credit to a faculty member's most recent institution. However, these highly productive faculty members make up only one percent of the overall faculty, and their influx (which is too recent to be captured by the current Academic Analytics data) will have a minimal effect on KU's citations profile.
Examining where faculty publish may yield insight into the citation deficit. Citation measures are sensitive to the choice of journals, some of which are read more often than others. Paying attention to where researchers publish relative to journals' prominence may improve citations.

Proper marketing of by KU's faculty may provide another route for $\mathrm{KU}$ to raise its citation counts. For example, citations generally increase when research appears in open access venues.

Although useful, hiring foundation professors or having faculty provide open access to their publications will not and cannot substantially increase KU's citation scores. Increasing scores will require centrally led, department-by-department analyses of how KU hires, mentors, and promotes its faculty.

${ }^{1}$ Publications include books, journal articles, conference presentations. More broadly, publications may include performances and exhibitions, but there currently are no standard measures of these and Academic Analytics does not include them. The present article focuses on books and journal articles.

2 Egghe, Leo (2006) Theory and practice of the g-index. Scientometrics, 69, No 1, pp. 131-152.

${ }^{3}$ Hirsch, J. E. (2005). An index to quantify an individual's scientific research output. Proceedings of the National Academy of Sciences, 102 (46): 16569-16572.

${ }^{4}$ The present paper ignores Academic Analytics data on conference presentations.

${ }^{5}$ A reminder: The book publication collection period covered 2005-2014; the journal article collection period covered 2011-2014. 